\title{
Expression of urocortin in rat lung and its effect on pulmonary vascular permeability
}

\author{
Yuqing Wu, Yinyan Xu, Hong Zhou, Jin Tao and Shengnan Li
}

Department of Pharmacology, Nanjing Medical University, Nanjing, 210029, P R China

(Requests for offprints should be addressed to S Li; Email: njmusnli@126.com)

\begin{abstract}
Urocortin (UCN), a newly identified, 40-amino-acid, corticotropin-releasing hormone $(\mathrm{CRH})$ structurally related peptide, has been demonstrated to be expressed in the central nervous system and many peripheral tissues of rats and man. This study aimed to investigate the expression profile of UCN in rat lung and the effect of UCN on lung vascular permeability. The expression of UCN mRNA was detected by reverse transcriptase PCR (RT-PCR). UCN peptide was measured by immunohistochemistry and Western blot analysis. We found that both UCN mRNA and peptide were obviously expressed in rat lung. Immunohistochemistry results showed that UCN peptide is mainly expressed in bronchial epithelium mucosa and alveolar epithelium. We also found that rats receiving inhalation aerosol of UCN had a significant elevation of lung vascular permeability compared with rats receiving vehicle and ovalbumin (OVA) by the Evans blue (EB) technique. UCN aerosol inhalation resulted in
\end{abstract}

obvious pulmonary congestion and edema observed under light microscope by hematoxylin and eosin (HE) staining. The nonselective peptide $\mathrm{CRH}$ receptor antagonist astressin markedly reduced lung vascular permeability triggered by UCN. Enhanced pulmonary vascular permeability induced by UCN was markedly inhibited by pretreatment with the mast-cell stabilizer cromolyn and histamine-1 $\left(\mathrm{H}_{1}\right)$ receptor antagonist azelastine respectively, but not by the leukotriene receptor antagonist montelukast. In summary, in the present study, we demonstrated for the first time that UCN is expressed in rat lung and contributes to an increase in lung vascular permeability through activation of $\mathrm{CRH}$ receptors. Mast cells and histamine may be involved in this effect of UCN. Peripherally produced UCN in lung may act as an autocrine and paracrine proinflammatory factor.

Journal of Endocrinology (2006) 189, 167-178

\section{Introduction}

Corticotropin-releasing hormone $(\mathrm{CRH})$ is a 41 -aminoacid neuropeptide, best known for its role in regulating the hypothalamic-pituitary adrenal axis in mammals (Vale et al. 1981, Rivier et al. 1983, Shibahara et al. 1983, Schulte et al . 1985, Chrousos 1995). By stimulating adrenocorticotropin hormone (ACTH) release from the pituitary (Vale et al. 1981, Linton et al. 1985) and, thus, cortisol secretion, centrally produced CRH exerts profound immunosuppressive effects (Chrousos 1995). More recently, a new member of the $\mathrm{CRH}$ family, urocortin (UCN), was cloned and shown to be expressed in the central nervous system of rats (Vaughan et al. 1995) and man (Donaldson et al. 1996). Rat UCN is a 40-amino-acid peptide with 45\% sequence identity to CRH (Vaughan et al. 1995), 95\% amino-acid identity with human UCN (Donaldson et al. 1996) and 63\% identity with the fish peptide, urotensin (Vaughan et al. 1995). UCN has central effects similar to those of CRH, including stimulation of ACTH secretion and appetite suppression (Spina et al. 1996).
There are two receptors for $\mathrm{CRH}$ and $\mathrm{UCN}$, the CRH receptor types 1 (CRH-R1) and 2 (CRH-R2) (Liaw et al. 1996, Vale et al. 1997). CRH has low affinity for CRH-R2 and high affinity for CRH-R1, whereas UCN has high affinity for both (Kishimoto et al. 1995). UCN has fourfold higher affinity than CRH for CRH-R1 and 40-fold higher affinity for CRH-R2 (Vaughan et al. 1995).

Besides central nervous system distribution and effects, $\mathrm{CRH}$ and UCN have also been shown to be present in many peripheral tissues, where, in contrast to their systemic, indirect immunosuppressive effects, they act as autocrine or paracrine proinflammatory factors (Karalis et al. 1991, Schulte et al. 1995). Indeed, many recent studies report the local production of immune CRH and UCN in various inflammatory sites, including carrageenin-induced granulomatous tissues (Karalis et al. 1991) and streptococcal cell wall- and adjuvant-induced arthritic joints of rats (Crofford et al. 1992), and the joints of patients with rheumatoid arthritis (RA) and osteoarthritis (OA) (Crofford et al. 1993, Masataka et al. 2001, Uzuki et al. 2001), as well as in some neurogenic skin disorders (Katsarou-Katsari et al. 2001), 
autoimmune thyroiditis and ulcerative colitis (Chrousos 1995, Saruta et al. 2004). Moreover, systemic administration of anti-CRH serum reduced carrageenin-induced subcutaneous inflammation (Karalis et al. 1991). UCN along with CRH may, therefore, participate in the pathophysiology of many inflammatory conditions.

Recent studies show that human cord blood-derived, cultured mast cells (hCBMC) and leukemic mast cells (HMC-1) are immunocytochemically positive for CRH and UCN. The ability of these mast cells to synthesize $\mathrm{CRH}$ and UCN was confirmed by showing mRNA expression with reverse transcriptase PCR (RT-PCR). Stimulation of IgE-sensitized hCBMC with anti-IgE results in secretion of more CRH and UCN (Kempuraj et al. 2004a). Moreover, CRH (Michael et al. 2003, Theoharides et al. 1998) and UCN (Singh et al. 1999a) induce mast cell degranulation and vascular permeability in rodent skin, but not in $\mathrm{W} / \mathrm{Wv}$ mast cell-deficient mice (Theoharides et al. 1998). High numbers of activated mast cells are present in endometriosis sites strongly positive for $\mathrm{CRH} / \mathrm{UCN}$. CRH and UCN may activate mast cells and contribute to the fibrosis and inflammation in endometriosis (Kempuraj et al. 2004b). Systemic or uterine stressful conditions may increase the incidence of spontaneous abortions by inducing the local release of $\mathrm{CRH}$ and $\mathrm{UCN}$, which then activate endometrial mast cells to secrete abortogenic tryptase and interleukin (IL)-8 (Bhuvaneshwari et al. 2003). These findings indicate that mast cells are not only a potential source, but also the target of CRH and UCN, which could have both autocrine and paracrine functions (Theoharides et al. 2004). This finding that mast cells secrete $\mathrm{CRH} / \mathrm{UCN}$ and are activated by it reinforces the bidirectional relationship between $\mathrm{CRH} / \mathrm{UCN}$ and mast cells in inflammatory conditions (Theoharides \& Cochrane 2004), especially in allergic inflammatory disorders exacerbated by stress. Furthermore, the expression of both UCN mRNA and peptide in human lymphocytes and Jurkat $\mathrm{T}$ lymphoma cells has been proven (Bamberger et al. 1998).

$\mathrm{CRH}$ has been detected in many peripheral tissues, including fetal lung (Keegan et al. 1994, Muglia et al. 1994). Although UCN has also been demonstrated to be considerably expressed peripherally, the expression of UCN and its biologic actions in lung have never been reported. In this study, we investigated and reported the expression profile of UCN in rat lung tissues at both mRNA and peptide level by RT-PCR, immunohistochemistry and Western blotting. On the basis of the already mentioned role of UCN in inflammation, we evaluated the effect of UCN on lung vascular permeability.

\section{Materials and Methods}

Animals

Healthy male Sprague-Dawley (SD) rats 6-8 weeks of age and weighing $250-300 \mathrm{~g}$ were provided by the
Experimental Animal Center of Nanjing Medical University. All the rats were housed three per cage, given free access to food and water, and maintained in animal facilities with filtered air on a diurnal lighting cycle. All the studies were carried out in agreement with the official recommendations of the Chinese Community guidelines.

\section{Collection of tissues}

Six rats were killed by decapitation and exsanguinated. After midline thoracotomy, lung tissues were collected from rats and either flash frozen in liquid nitrogen for RNA and protein extraction, or fixed in 10\% neutral formalin, embedded in paraffin, and sectioned onto polyL-lysine-coated slides for immunohistochemical analysis and hematoxylin and eosin (HE) staining.

\section{Semiquantitative RT-PCR for UCN $m R N A$}

Total RNA was extracted from $30 \mathrm{mg}$ lung tissues with RNeasy Mini Kit (Qiagen), according to the manufacturer's guidelines, and quantified by UV absorption. The following procedures and chemicals for RT-PCR were used. For cDNA synthesis (Qiagen), $20 \mu \mathrm{l}$ reverse transcription mixture containing total RNA $2 \mu \mathrm{g}$, each dNTP mixture $0.5 \mathrm{mmol} / \mathrm{l}$, Oligo-dT primer $0.5 \mu \mathrm{mol} / \mathrm{l}$, RNase inhibitor $10 \mathrm{U}$, and Omniscript reverse transcriptase (Qiagen) $4 \mathrm{U}$ were well mixed and incubated at $37^{\circ} \mathrm{C}$ for $60 \mathrm{~min}$. Specific primers for rat GAPDH (an internal standard) and UCN were synthesized from published sequences (Baigent \& Lowry 2000):

- GAPDH primers - forward primer: $5^{\prime}-\mathrm{TCC}$ CAG AGC TGA ACG GGA AGC TCA CTG-3'; reverse primer: 5'-TGG AGG CCA TGT AGG CCA TGA GGT CCA-3'

- UCN primers - forward primer: $5^{\prime}-\mathrm{GCT}$ ACG CTC CTG GTA GCG TTG CTG CTT CTG-3'; reverse primer: 5'-GCC GAT CAC TTG CCC ACC GAG TCG AAT ATG-3'.

All primers were synthesized by Takara Co (Dalian, China) with the product sizes 339 and $356 \mathrm{bp}$ respectively. PCR reaction constituents were as follows: $2 \mu \mathrm{l}$ cDNA mixture was subjected to amplification in $30 \mu \mathrm{l}$ final volume with $\mathrm{MgCl}_{2} 1.5 \mathrm{mmol} / \mathrm{l}$, each dNTP $0.2 \mathrm{mmol} / \mathrm{l}, 12 \mathrm{pmol}$ of each primer, and $2 \mathrm{U}$ of Taq DNA polymerase in the reaction buffer. PCR reaction conditions were as follows: $95^{\circ} \mathrm{C}$ for $5 \mathrm{~min}$ and then $94{ }^{\circ} \mathrm{C}$ for $30 \mathrm{~s}, 52{ }^{\circ} \mathrm{C}$ for $40 \mathrm{~s}, 72{ }^{\circ} \mathrm{C}$ for $40 \mathrm{~s}$, for 35 cycles; and $72{ }^{\circ} \mathrm{C}$ for $10 \mathrm{~min}$ to end the reaction. PCR products of $10 \mu \mathrm{l}$ were separated by $1 \cdot 2 \%$ agarose gel electrophoresis and visualized by ethidium bromide staining. The density of each band was measured by UVP gel analysis system. Control PCR reactions were used to overcome the possibility of amplifying genomic DNA in these circumstances. 


\section{Immunohistochemistry for UCN peptide}

Immunohistochemical staining was performed with the avidinbiotin peroxidase complex. Lung tissue specimens were preserved in 10\% neutral formalin, embedded in paraffin, serially sectioned onto microscope slides at a thickness of $5 \mu \mathrm{m}$, and then deparaffinized. The slides were immersed for $10 \mathrm{~min}$ in $3 \%$ hydrogen peroxide to deplete endogenous peroxidase activity. Nonspecific binding sites were saturated by exposure to $0 \cdot 2 \%$ BSA and normal goat serum for $20 \mathrm{~min}$. Rabbit polyclonal, UCNspecific antibody (Sigma; 1:100 dilution) that reacts specifically with urocortin and does not cross-react with structurally related CRH family peptides, including CRH, sauvagine and urotensin, or control normal rabbit IgG, was applied to tissue sections and incubated in a humidified chamber at $37^{\circ} \mathrm{C}$ for $60 \mathrm{~min}$. Then the slides were washed with PBS for $10 \mathrm{~min}$. Biotinylated goat antirabbit IgG was applied to tissue sections, and the slides were incubated at room temperature for $30 \mathrm{~min}$. They were then washed with PBS for $10 \mathrm{~min}$, followed by incubation with prepared streptavidin biotinylated peroxidase complex for $45 \mathrm{~min}$ and washed with PBS for 10 min. Finally, color was developed by adding $3,3^{\prime}-$ diaminobenzidine to the sections. The sections were counterstained with hematoxylin, dehydrated and observed under light microscope. Positive staining was indicated by brownish deposits.

\section{Western blot analysis for UCN peptide}

The lung tissues from rats were homogenized and centrifuged in ice-cold lysis buffer containing protease inhibitor phenylmethylsulfonyl fluoride. The pellets were discarded. The protein content of the crude preparations was measured by the Bradford method with lyophilized BSA (Bio-Rad) as standard. The protein sample $(50 \mu \mathrm{g})$ was separated on a $15 \%$ SDS-polyacrylamide gel for $70 \mathrm{~min}$ and electrophoretically transferred onto a nitrocellulose membrane in Tris-glycine transfer buffer containing 20\% methanol in a Trans-Blot cell (Bio-Rad) for $35 \mathrm{~min}$. A low-molecular-weight marker (Rainbowmarker; Amersham-Buchler) served as standard. Membranes were blocked in 5\% instant nonfat dry milk in Tris-buffered saline, washed in Tris-buffered saline, and probed with rabbit-raised antibody against UCN (Sigma; 1:1000 dilution) that reacts specifically with urocortin and does not cross-react with structurally related CRH family peptides including CRH, sauvagine and urotensin. The immunoblots were subsequently washed and incubated in horseradish peroxidase-coupled antirabbit IgG antibody (1:5000) for $1 \mathrm{~h}$. The bound antibodies were visualized by enhanced chemiluminescence with the ECL system (Amersham Pharmacia Biotech) and exposure to X-OMAT film (Kodak). Western blots were repeated five times with qualitatively similar results.

\section{Detection of Evans blue (EB) extravasation}

To investigate the effect of UCN on pulmonary microvascular permeability, $10^{-6}, 10^{-7}$ and $10^{-8} \mathrm{M} \mathrm{UCN}$ was inhaled by aerosol respectively at flow rate of $0.5 \mathrm{ml}$ per min for $10 \mathrm{~min}$. Rats in negative control groups were treated with normal saline (NS) and ovalbumin (OVA) respectively, and the values were used as normal control for all the EB extravasation experiments. Rats in positive control were treated with histamine. To study the effects of cromolyn, astressin, azelastine and montelukast on EB extravasation triggered by $10^{-6} \mathrm{M} \mathrm{UCN}$, different concentrations of cromolyn, astressin, azelastine and montelukast were inhaled by aerosol respectively $20 \mathrm{~min}$ before treatment of UCN. Eight rats in each group were used for experiments. EB, a nonradioactive diazo dye that binds tightly to albumin, is a sensitive marker for early pulmonary edema (Udaka et al. 1970, Patterson et al. 1992). Prolonged perfusion with EB does not alter vasoreactivity or water content in isolated, perfused rat lungs (Dallal \& Chang 1994). A solution of $1 \%$ EB (containing $100 \mathrm{U}$ heparin per $\mathrm{ml}$ solution) was prepared in sterile water and stored at $4{ }^{\circ} \mathrm{C}$. After inhalation aerosol of UCN, the rats were injected intravenously with $1 \% \mathrm{~EB}(2 \mathrm{ml} / \mathrm{kg})$ via tail vein. The animals were anesthetized $60 \mathrm{~min}$ later by intraperitoneal injection with sodium pentobarbital $(30 \mathrm{mg} / \mathrm{kg})$. After midline thoracotomy, the superior and inferior vena cava were ligated, the aorta was transected, and $20 \mathrm{ml}$ normal saline solution were injected into the right ventricle at a pressure of $20 \mathrm{cmH}_{2} \mathrm{O}$ to wash out the pulmonary intravascular content. A sample of lung tissue was weighed, immersed in N,N-dimethylformamide, and homogenized. The homogenate was incubated at $50{ }^{\circ} \mathrm{C}$ for $36 \mathrm{~h}$ and centrifuged at $3900 \mathrm{~g}$ for $10 \mathrm{~min}$. The optical density of $1 \mathrm{ml}$ supernatant was measured at $620 \mathrm{~nm}$ wavelength, and the EB concentration was determined from a standard curve of $\mathrm{EB}-\mathrm{N}, \mathrm{N}$-dimethylformamide solutions. Microvascular permeability was expressed as micrograms of EB per gram lung tissue.

\section{Histopathologic observation}

In this study, we investigated the effect of UCN on lung congestion and edema induced by increased lung vascular permeability. The animals were killed by decapitation $60 \mathrm{~min}$ after inhalation aerosol of UCN. The lower lobes of the right lungs were excised, fixed in 10\% neutralbuffered formalin for at least $24 \mathrm{~h}$, and processed routinely. After being embedded in paraffin, the tissues were cut into 5- $\mu \mathrm{m}$-thick sections and stained with $\mathrm{HE}$ before examination under light microscope.

\section{Statistical analysis}

All values were expressed as mean \pm S.D. The significance for the difference between the groups was analyzed with 

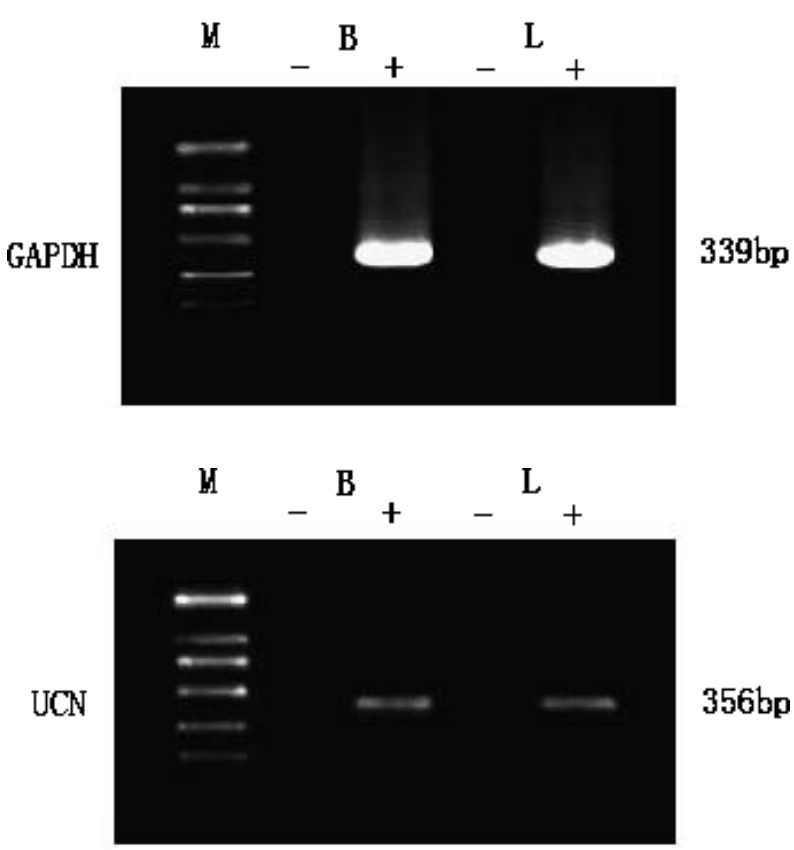

$356 \mathrm{bp}$

Figure 1 Semiquantitative RT-PCR carried out on samples of brain (B) and lung (L) to detect the presence of GAPDH and UCN transcripts in these tissues. Thirty-five PCR cycles were carried out for all reactions. $M$, DNA ladder marker; -, control reaction without reverse transcriptase; + , PCR reaction with the addition of reverse transcriptase. The brain provided a positive control test.

SPSS $10 \cdot 0$ by one-way ANOVA. Differences were considered significant when $P<0 \cdot 05$.

\section{Results}

\section{Semiquantitative RT-PCR}

The results of RT-PCR with UCN primers in this study demonstrated that UCN mRNA is expressed in rat lung tissues. The predicted size band was detected in all the lung samples from rats. Positive control performed with total RNA of rat brain also showed the expected band. Negative control performed with no reverse transcriptase added to the reaction yielded no detectable band, indicating no evidence of either contamination or the presence of genomic DNA. Primers specific for GAPDH generated the expected 339-nucleotide band in all cases. The brightness of the GAPDH bands was similar, showing that similar amounts of mRNA were used for each sample (Fig. 1). The gel bands illustrated in Fig. 1 represent the majority of the results obtained and could be reproduced on at least four occasions. Brain mRNA provided an ideal positive control for all the PCR reactions. The brightness of the UCN bands amplified from lung and brain mRNA appeared to be similar.
Immunohistochemistry for UCN in lung tissues

For immunohistochemistry, the lung tissues were immunostained with specific antibody to UCN. The results showed that UCN peptide was mainly expressed in bronchial epithelium mucosa and alveolar epithelium. The cytoplasm was uniformly stained brown, indicating that bronchial epithelium mucosa and alveolar epithelium cells contain UCN peptide (Fig. 2B). UCN immunoreactivity was also detected in lung vascular smooth muscle cells and vascular endothelial cells (Fig. 2D). However, no staining for UCN in airway smooth muscle cells was found (Fig. 2B). Negative controls stained by normal rabbit serum instead of UCN antiserum revealed no positive immunostaining (Fig. $2 \mathrm{~A}$ and $\mathrm{C}$ ).

\section{Western blot analysis}

Subsequently, to validate our findings, we further investigated the expression of UCN peptide in rat lung tissue by Western blot analysis. In this study, UCN peptide expression was found in all six rat lung specimens. As shown in Fig. 3, rat UCN peptide was detected in lung as a single band of approximately $5 \mathrm{kDa}$ by Western blot analysis with a UCN-specific antibody. No band was found with normal serum instead of UCN-specific antibody. The band illustrated in Fig. 3 represents the majority of the results obtained and could be reproduced on at least four occasions.

\section{Effect of UCN on EB extravasation}

The effect of UCN on pulmonary microvascular permeability was assessed by extraction of extravasated EB. There was very little EB extravasation from pulmonary capillaries in NS and OVA control groups (22.5 \pm 9.73 ; $28 \cdot 17 \pm 9 \cdot 62 \mu \mathrm{g} / \mathrm{g}$ lung tissue). Inhalation aerosol of UCN $\left(10^{-7}\right.$ and $\left.10^{-6} \mathrm{M}\right)$ induced a marked increase in lung vascular permeability, as shown by tissue extravasation of i.v. injected EB. There was more EB exudation from lung blood vessel, with increasing doses of UCN $(69 \cdot 5 \pm 12 \cdot 91 ; 81 \cdot 67 \pm 22 \cdot 46 \mu \mathrm{g} / \mathrm{g}$ lung tissue $)$. It was statistically significant when compared with that from control group $(P<0 \cdot 01)$. Enhanced lung vascular permeability induced by histamine was performed as a positive control. The results indicate that UCN may be one of the most potent rat lung vasodilators. Inhalation aerosol of UCN at a concentration as low as $10^{-8} \mathrm{M}$ did not enhance lung vascular permeability markedly (33.0 $\pm 12 \cdot 52 \mu \mathrm{g} / \mathrm{g}$ lung tissue, $P>0 \cdot 05$, vs control) (Fig. 4).

\section{Effect of astressin on pulmonary microvascular permeability triggered by UCN}

There was very little EB extravasation from pulmonary capillaries in NS and OVA control groups. However, rats treated 

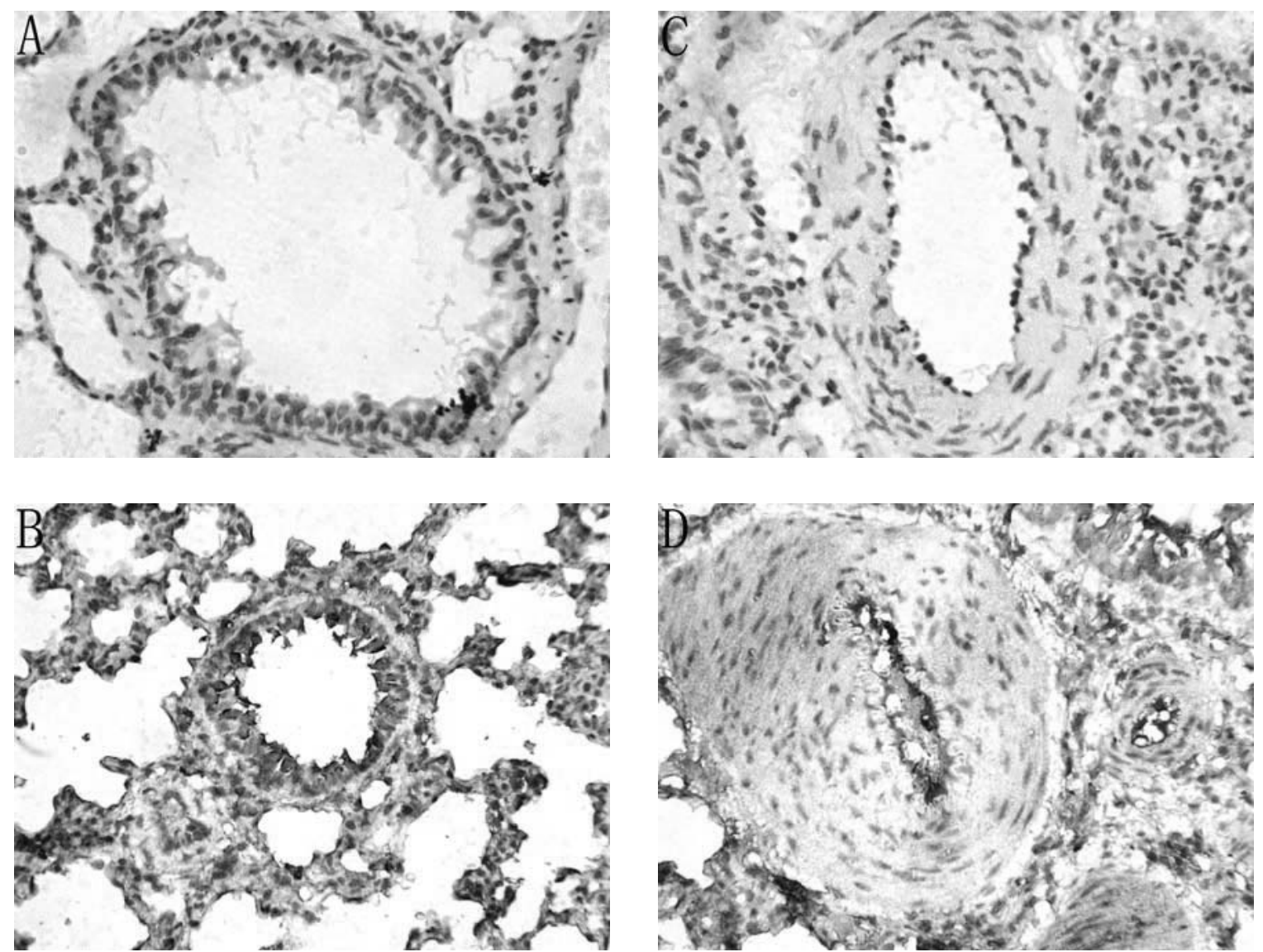

Figure 2 Immunohistochemistry for UCN in rat lung tissues. Immunoreactivity appears brown as a result of DAB colorimetric reaction. $\times$ 400. (A) Bronchus and lung alveolus stained with normal rabbit IgG. (B) Bronchus and lung alveolus stained with rabbit anti-UCN antibody. (C) Lung blood vessel stained with normal rabbit IgG. (D) Lung blood vessel stained with rabbit anti-UCN antibody.

with inhalation aerosol of UCN at a concentration of $10^{-6} \mathrm{M}$ increased lung vascular permeability significantly. We then investigated whether the effect of UCN was mediated by specific CRH receptors, but we did not find any effect of the nonselective peptide $\mathrm{CRH}$ receptor antagonist astressin alone on EB extravasation (data not shown). However, inhalation aerosol of different concentration of astressin $\left(10^{-7} \mathrm{M}, 10^{-6} \mathrm{M}\right.$ and $\left.10^{-5} \mathrm{M}\right)$ $20 \mathrm{~min}$ before the inhalation aerosol of $\operatorname{UCN}\left(10^{-6} \mathrm{M}\right)$ markedly inhibited the response to UCN (Fig. 5).

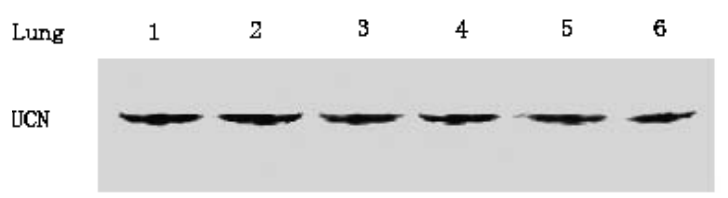

XII

Figure 3 Expression of UCN peptide in rat lung tissues by Western blot analysis. Lanes $1-6$ represent six rats respectively. MW, molecular weight.
Effect of cromolyn on pulmonary microvascular permeability triggered by UCN

It was hypothesized that UCN-induced vascular permeability may be secondary to the release of vasodilatory molecules from lung mast cells. To investigate whether mast cells are involved in the effect of UCN on lung vascular permeability, we used the mast-cell stabilizer cromolyn. UCN at a concentration of $10^{-6} \mathrm{M}$ induced an increase in EB extravasation. This effect was attenuated by inhalation aerosol of different concentration of cromolyn $\left(10^{-6} \mathrm{M}, 10^{-5} \mathrm{M}\right.$ and $\left.10^{-4} \mathrm{M}\right) 20 \mathrm{~min}$ before the inhalation aerosol of $\mathrm{UCN}\left(10^{-6} \mathrm{M}\right)$. It showed that cromolyn inhibited EB extravasation induced by UCN. However, cromolyn at a concentration as high as $10^{-4} \mathrm{M}$ could not inhibit the effect of UCN on lung vascular permeability entirely. There is a statistical difference between NS or OVA control and cromolyn $\left(10^{-4} \mathrm{M}\right)$ plus UCN $\left(10^{-6} \mathrm{M}\right)$ group $(P<0 \cdot 05)$ (Fig. 6). 


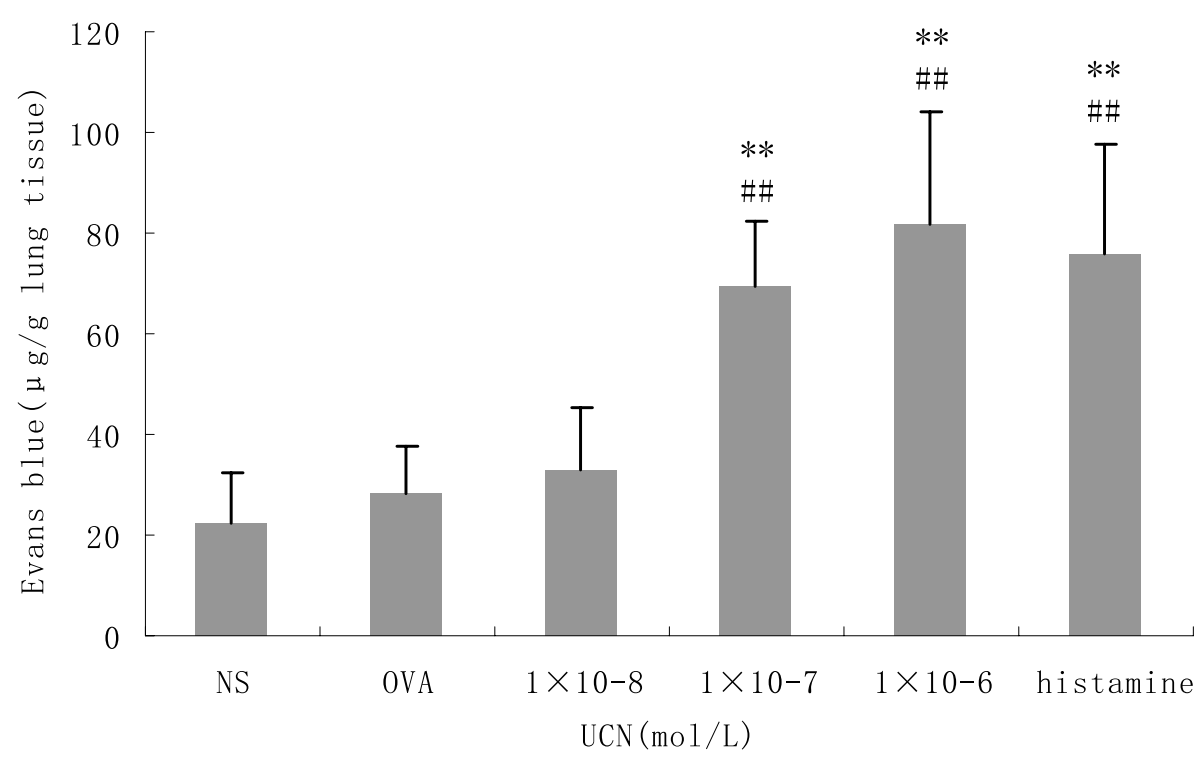

Figure 4 Pulmonary vascular permeability ( $\mu \mathrm{g} E B / g$ lung tissue) measured by EB technique after inhalation aerosol of increasing concentrations of UCN. NS, normal saline; OVA, ovalbumin. Data

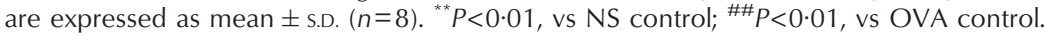

Effect of azelastine on pulmonary microvascular permeability triggered by UCN

To examine whether the mast cell-derived vasodilatory molecule histamine mediated the effect of $\mathrm{UCN}$, the $\mathrm{H}_{1}$ receptor antagonist azelastine was administered by aerosol before the treatment with UCN. EB extravasation in response to UCN $\left(10^{-6} \mathrm{M}\right)$ was reduced by pretreatment with azelastine. The content of exudated EB was reduced from $81 \cdot 67 \pm 22 \cdot 46$ to $52 \cdot 5 \pm 16 \cdot 26, \quad 47 \cdot 17 \pm 17 \cdot 33$ and $44 \cdot 67 \pm 15 \cdot 2 \mu \mathrm{g} \mathrm{EB} / \mathrm{g}$ lung tissue by pretreatment with $10^{-6}, 10^{-5}$ and $10^{-4} \mathrm{M}$ azelastine respectively $(P<0 \cdot 05, \quad P<0 \cdot 01)$. These results suggest that histamine is the major molecule mediating UCN-induced EB extravasation. However, azelastine at a

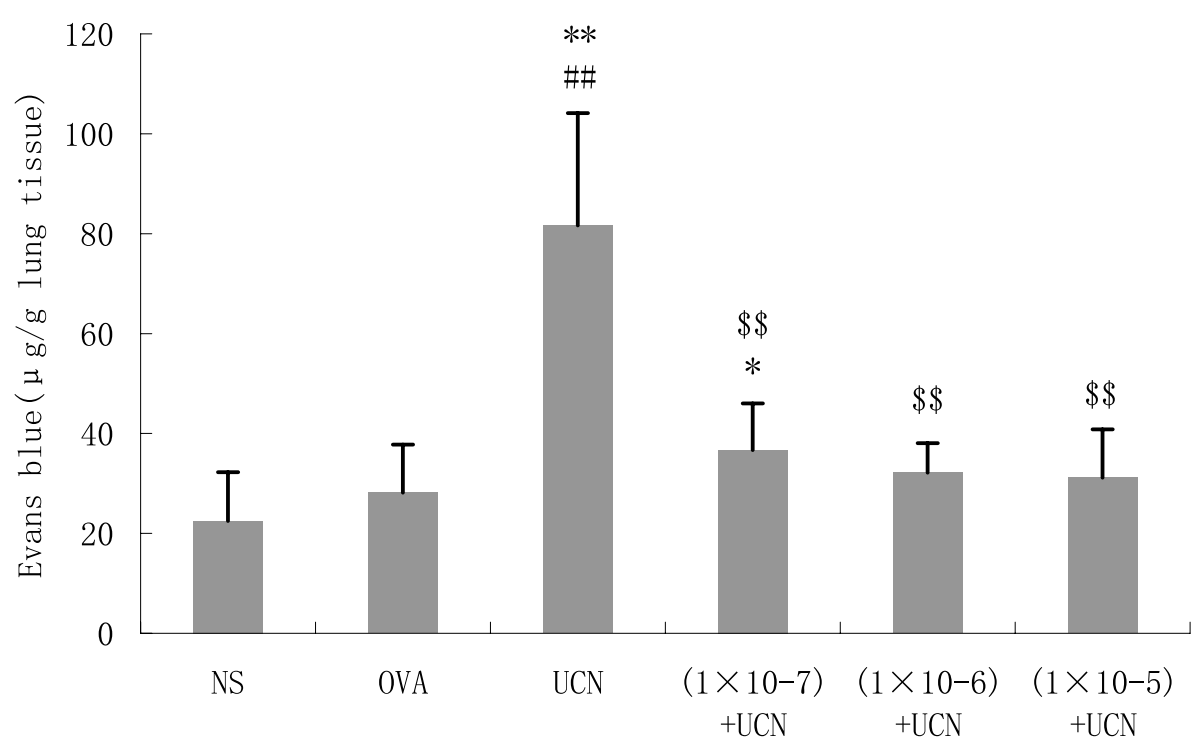

Astressin (mol/L)

Figure 5 Effect of astressin on pulmonary vascular permeability ( $\mu \mathrm{g} E B / g$ lung tissue) induced by inhalation aerosol of $10^{-6} \mathrm{M} \cup \mathrm{CN}$ measured by EB technique. Data are expressed as mean \pm S.D. $(n=8) .{ }^{*} P<0 \cdot 05,{ }^{* *} P<0 \cdot 01$, vs NS control; ${ }^{\# \#} P<0 \cdot 01$, vs OVA control; ${ }^{\$ \$} P<0 \cdot 01$, vs UCN group. 


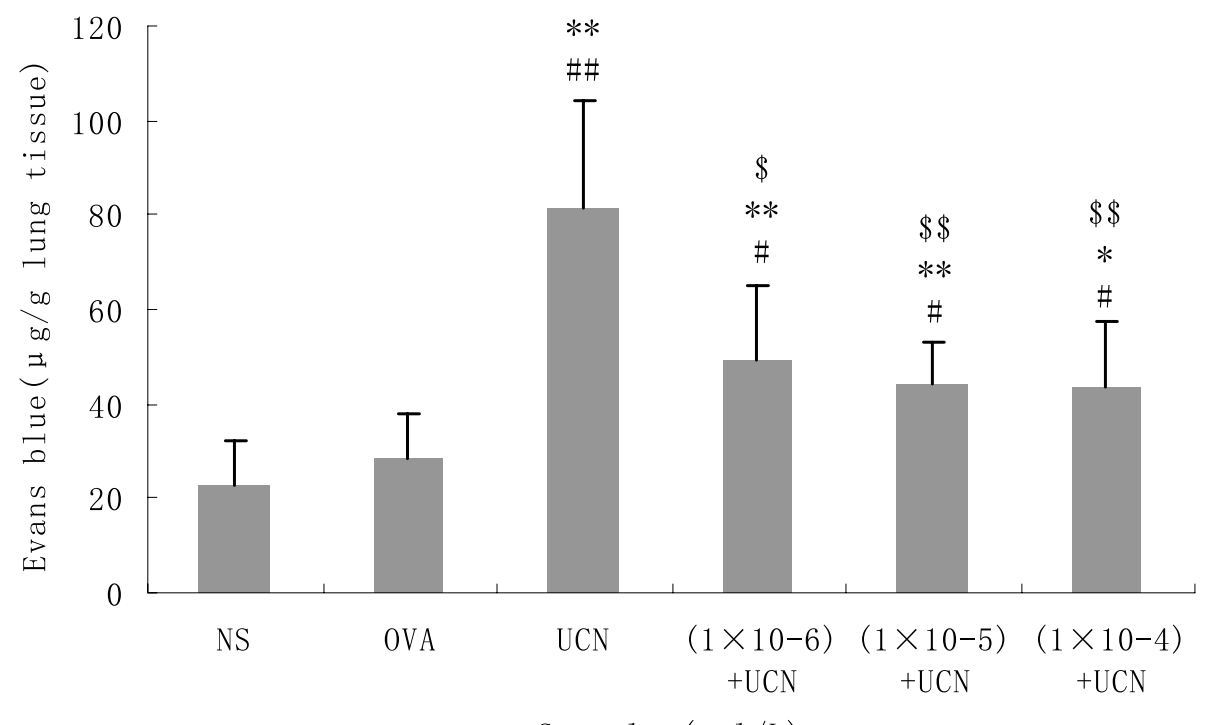

Cromolyn $(\mathrm{mol} / \mathrm{L})$

Figure 6 Effect of cromolyn on pulmonary vascular permeability ( $\mu \mathrm{g} \mathrm{EB} / \mathrm{g}$ lung tissue) induced by inhalation aerosol of $10^{-6} \mathrm{M} \cup \mathrm{CN}$ measured by EB technique. Data are expressed as mean \pm S.D. $(n=8) .{ }^{*} P<0 \cdot 05,{ }^{* *} P<0 \cdot 01$, vs NS control; ${ }^{\#} P<0 \cdot 05,{ }^{\# \#} P<0 \cdot 01$, vs OVA control; ${ }^{\$} P<0 \cdot 05, \$ \$ P<0 \cdot 01$, vs UCN group.

concentration as high as $10^{-4} \mathrm{M}$ could not entirely inhibit enhanced lung vascular permeability triggered by UCN. It was statistically significant when compared with NS or OVA control group $(P<0 \cdot 05)$ (Fig. 7$)$.

\section{Effect of montelukast on pulmonary microvascular permeability triggered by UCN}

As demonstrated in Fig. 8, inhalation aerosol of UCN increased EB extravasation from pulmonary capillaries significantly. To examine whether the vasodilatory molecule leukotriene mediated the vasodilatory effect of $\mathrm{UCN}$, the leukotriene receptor antagonist montelukast was administered by aerosol before treatment with UCN. Although EB extravasation from pulmonary capillaries in response to $\mathrm{UCN}\left(10^{-6} \mathrm{M}\right)$ was a little reduced by pretreatment with $10^{-6}, 10^{-5}$ and $10^{-4} \mathrm{M}$ montelukast respectively, there was no statistically significant difference between pretreatment with and no pretreatment with montelukast $(P>0 \cdot 05)$. Our results show that montelukast cannot markedly inhibit the increased lung vascular permeability induced by inhalation aerosol of UCN. These results suggest that leukotrine is not the major molecule mediating UCN-induced EB extravasation.

\section{Histopathologic observations in lung tissue}

Observed under light microscope by HE staining, rat lung tissue sections in normal control showed normal alveolar architecture (Fig. 9A). After inhalation aerosol of UCN, marked lung histopathologic abnormalities were observed, such as congestion, edema and alveolar septum thickening in interstitial tissue (Fig. 9B). This suggests that inhalation aerosol of UCN increases lung vascular permeability significantly. After pretreatment with astressin, cromolyn and azelastine, pulmonary congestion and edema induced by UCN were obviously attenuated (Fig. 9C-E). Pretreatment with montelukast did not significantly lighten the pulmonary congestion and edema triggered by UCN (Fig. 9F).

\section{Discussion}

UCN was identified initially as a neuropeptide expressed in the central nervous system (Vaughan et al. 1995). In this study, we demonstrated for the first time the expression of UCN mRNA and peptide in rat lung tissues. The expression of UCN was predominantly detected in bronchial epithelium mucosa and alveolar epithelium. Immunohistochemistry of UCN in serial tissue sections revealed that UCN peptide is mainly expressed in cytoplasm. In addition, the present results showed that inhalation aerosol of UCN can increase pulmonary vascular permeability significantly in rats through activation of $\mathrm{CRH}$ receptors. Mast cells and histamine may also be involved in this process as important effector cells and an inflammatory mediator.

UCN has been identified outside the central nervous system in many peripheral tissues such as gastrointestinal tract, testis, cardiac myocytes, thymus and spleen (Oki et al. 1998, Okosi et al. 1998, Baigent \& Lowry 2000). 


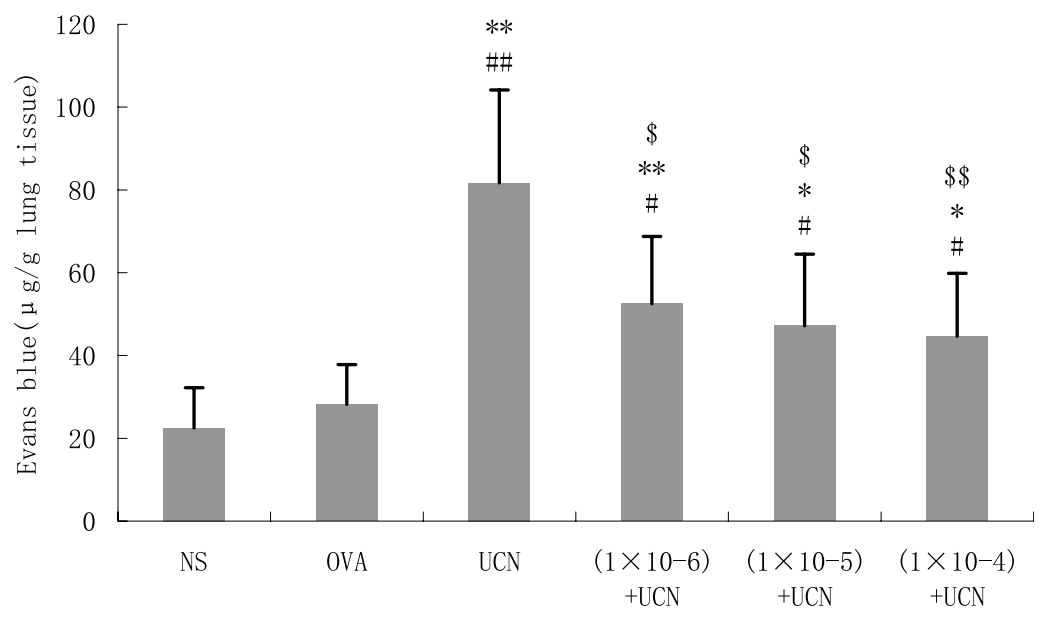

Azelastine (mol/L)

Figure 7 Effect of azelastine on pulmonary vascular permeability ( $\mu \mathrm{g} E B / g$ lung tissue) induced by inhalation aerosol of $10^{-6} \mathrm{MUCN}$ measured by EB technique. Data are expressed as mean \pm S.D. $(n=8)$. ${ }^{*} P<0 \cdot 05,{ }^{* *} P<0 \cdot 01$, vs NS control; ${ }^{\#} P<0 \cdot 05$, ${ }^{\# \# P} P<0 \cdot 01$, vs OVA control; ${ }^{\$} P<0 \cdot 05,{ }^{\$} P<0 \cdot 01$, vs $\cup C N$ group.

Lower levels of UCN mRNA have been detected in the kidney and liver (Kageyama et al. 1999), and UCN has been detected in the human skin (Slominski et al. 2000), placenta and fetal membranes (Petraglia et al. 1996). However, the expression profile of UCN in lung has never been reported. In the present study, we found that amplification of cDNA with UCN-specific primers was detected in all rat lung samples by RT-PCR analysis. This is the first report that UCN mRNA is stably expressed in rat lung tissues. To further validate our findings, Western blotting and immunohistochemistry analysis were performed to investigate whether UCN peptide is expressed in rat lung tissues. The expected results were also obtained. The expression of UCN peptide was found by Western blot analysis in all six rat lung specimens. The band size obtained in experiments was consistent with the expected size of UCN peptide. The results of immunohistochemistry showed that UCN peptide is mainly expressed in bronchial epithelium mucosa and alveolar epithelium. The vascular smooth muscle cells and blood vessel endothelial cells were also positively stained. However, staining for UCN in airway smooth muscle cells was not found. These results suggest that bronchial epithelium mucosa and alveolar epithelium

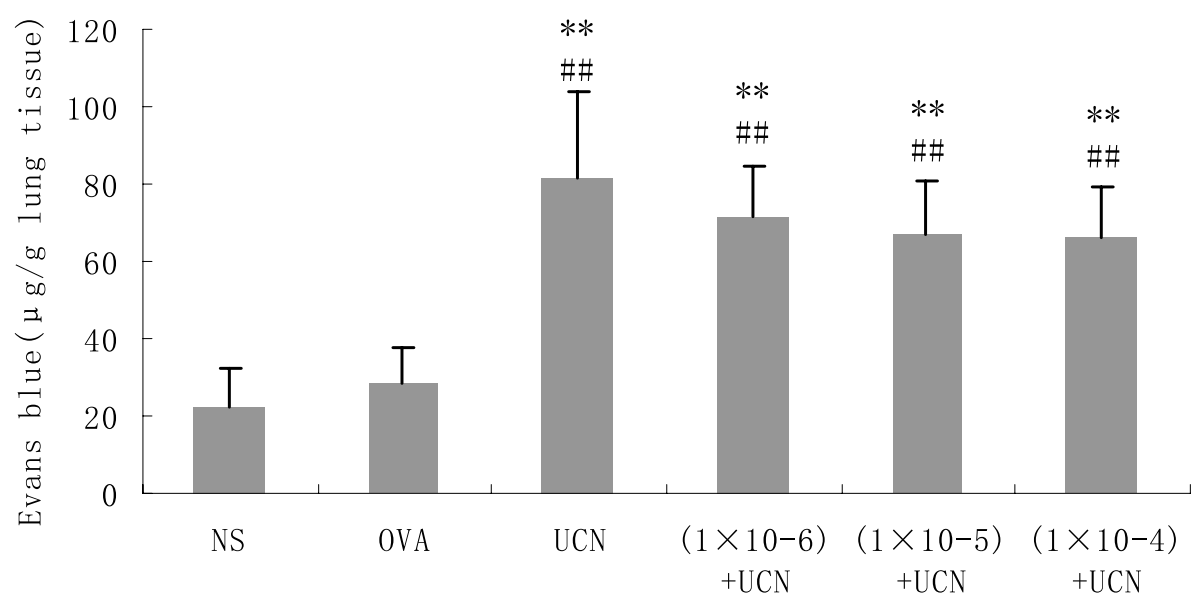

Montelukast (mol/L)

Figure 8 Effect of montelukast on pulmonary vascular permeability ( $\mu \mathrm{g} \mathrm{EB} / \mathrm{g}$ lung tissue) induced by inhalation aerosol of $10^{-6} \mathrm{MUCN}$ measured by EB technique. Data are expressed as

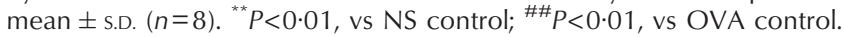



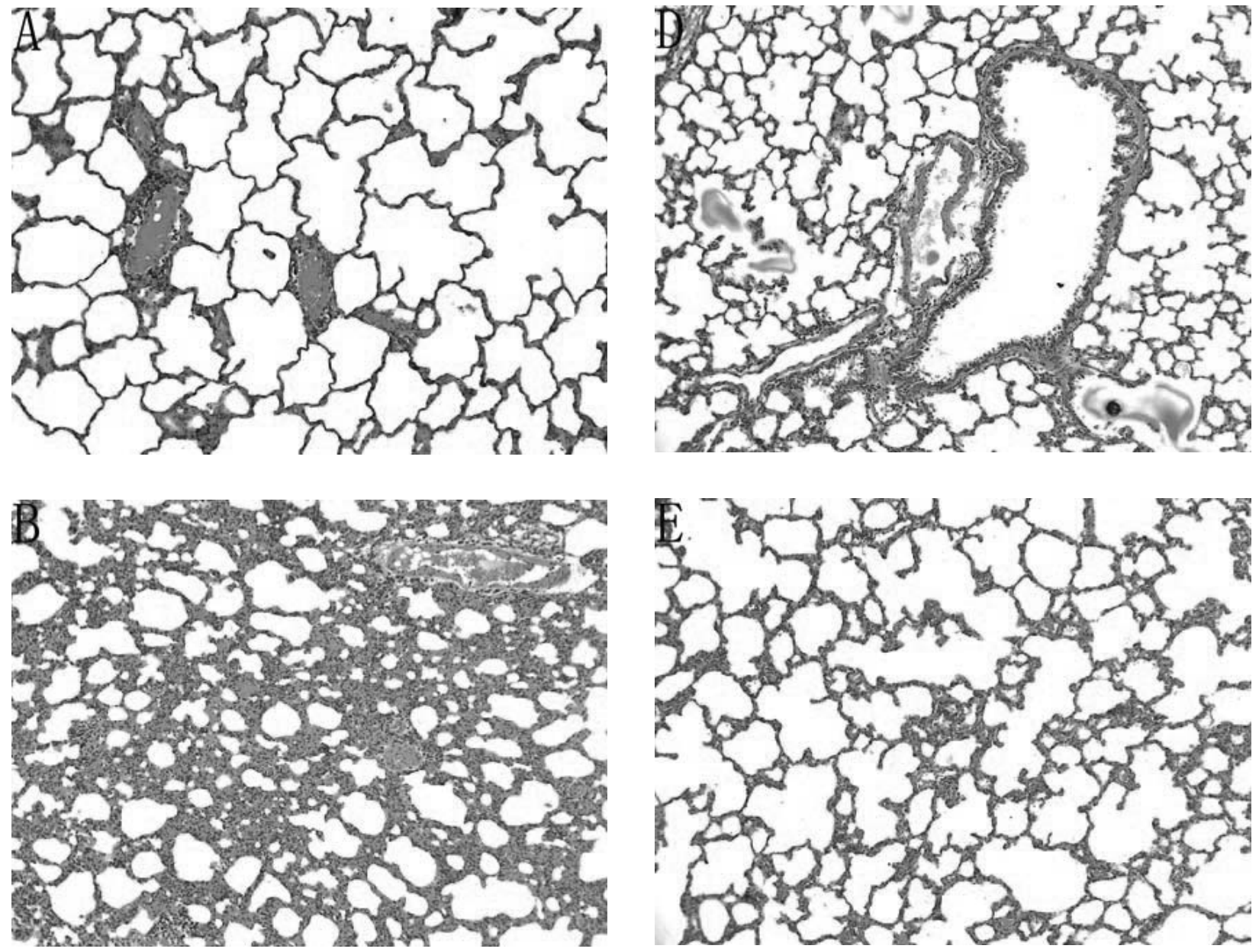

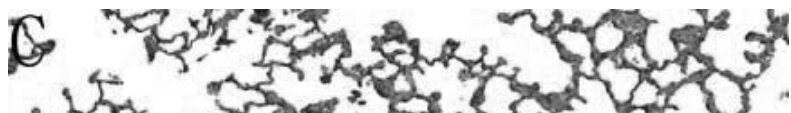

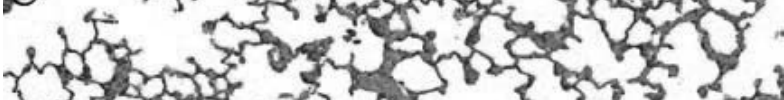

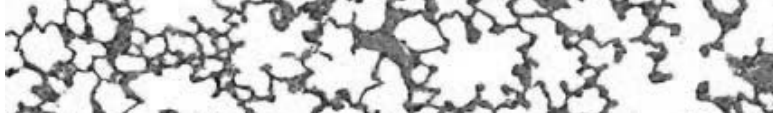
Fin

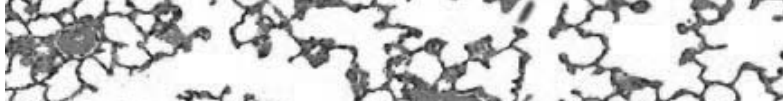

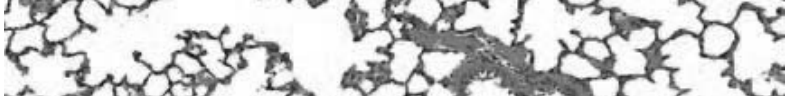

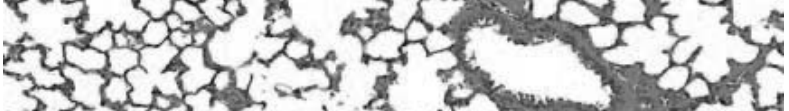
re

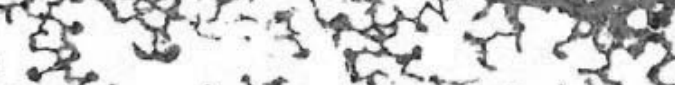

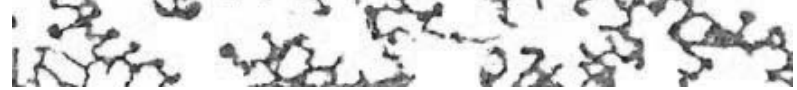

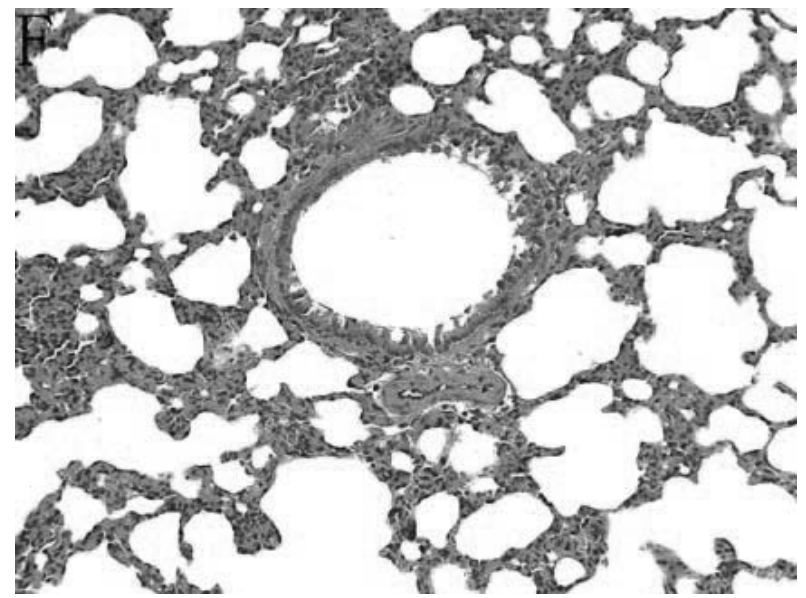

Figure 9 Observation of congestion and edema in lung interstitial tissue of rat under light microscope. (A) Inhalation aerosol of OVA. (B) Inhalation aerosol of $10^{-6} \mathrm{M} \cup \mathrm{CN}$. (C) Pretreatment with $10^{-5} \mathrm{M}$ astressin 20 min before inhalation aerosol of $10^{-6} \mathrm{M} \cup \mathrm{CN}$. (D) Pretreatment with $10^{-4} \mathrm{M}$ cromolyn $20 \mathrm{~min}$ before inhalation aerosol of $10^{-6} \mathrm{M}$ UCN. (E) Pretreatment with $10^{-4} \mathrm{M}$ azelastine 20 min before inhalation aerosol of $10^{-6} \mathrm{M} \mathrm{UCN}$. (F) Pretreatment with $10^{-4} \mathrm{M}$ montelukast 20 min before inhalation aerosol of $10^{-6} \mathrm{M}$ UCN. HE $\times 100$. 
may be important sources of endogenous UCN in lung tissues.

Previous studies reported that acute stress increases skin $\mathrm{CRH}$ that can trigger mast cell-dependent vascular permeability and that intradermal injection of UCN can induce skin mast-cell degranulation and increase vascular permeability. The actions of both CRH and UCN can be inhibited by pretreatment with the mast-cell stabilizer disodium cromoglycate (cromolyn) (Singh et al. 1999a 1999b, Michael et al. 2003). In the present study, we report for the first time that UCN increases pulmonary vascular permeability significantly in rats. We show that the extravasated EB in lung tissues is markedly increased after inhalation aerosol of $10^{-6}$ and $10^{-7} \mathrm{M}$ UCN. UCN aerosol inhalation resulted in obvious pulmonary congestion and edema observed under light-microscope HE staining.

To investigate whether the effect of UCN is mediated by specific CRH receptors, we pretreated the rats with astressin before administration of UCN. We found that $\mathrm{UCN}$-induced edema and EB extravasation in rat lung tissues were attenuated significantly by pretreatment with astressin. UCN-induced EB extravasation was reduced by astressin nearly to the level in normal control. The finding that the nonselective peptide $\mathrm{CRH}$ receptor antagonist astressin reduces vascular permeability triggered by $\mathrm{UCN}$ indicates that the effect of $\mathrm{UCN}$ is mediated by $\mathrm{CRH}$ receptors.

Our findings also show that the enhanced pulmonary vascular permeability induced by $10^{-6} \mathrm{M} \mathrm{UCN}$ is clearly inhibited by pretreatment with the mast-cell membrane stabilizer cromolyn. However, cromolyn at a concentration as high as $10^{-4} \mathrm{M}$ cannot inhibit the effect of UCN on lung vascular permeability entirely. This suggests that enhanced vascular permeability in lung induced by UCN may involve mechanisms other than mast-cell degranulation.

Azelastine is an antihistamine agent and has been shown to inhibit the release of histamine from rat mast cells after immunologic and nonimmunologic stimuli, as well as antagonize the proinflammatory effects of histamine (Chand et al. 1985, Mosges \& Klimek 1998, Takao et al. 1999). Here, we also report that pretreatment with azelastine inhibits vascular permeability induced by inhalation aerosol of $10^{-6} \mathrm{M}$ UCN. It has been shown that rat pleural mast cells secrete about 30\% histamine in response to CRH (Boucher et al. 1996). Our results suggest that UCN may stimulate histamine release through CRH receptors expressed on lung mast cells, which can increase lung vascular permeability. Histamine appears to be one of the main mediators involved in the in situ effect of UCN because the $\mathrm{H}_{1}$ receptor antagonist azelastine inhibited most of the vasodilatory response. However, even $10^{-4} \mathrm{M}$ azelastine could not reduce the EB extravasation induced by UCN to the normal control level, suggesting that histamine is not the only factor in the enhanced vascular permeability in lung induced by UCN.
Cysteinyl leukotriene (CysLT) is a potent proinflammatory mediator. It has been recognized that leukotriene can increase vascular permeability and mucus secretion. To examine whether the vasodilatory molecule leukotriene mediated the vasodilatory effect of UCN, the cysteinyl leukotriene receptor antagonist montelukast was inhaled by aerosol before treatment with UCN. The results showed that montelukast failed to inhibit the increased pulmonary vascular permeability triggered by UCN, suggesting that leukotriene may not be the main inflammatory factor involved in the in situ vasodilatory effect of UCN.

In contrast, Turnbull et al. (1996) demonstrated that edema owing to thermal injury in rats is inhibited by systemic UCN treatment, suggesting that UCN may decrease vascular permeability. However, the pharmacologic doses of UCN administered i.v. had probably produced hypotension, decreasing the ability of the animals to mount a full peripheral inflammatory response. Recently, Torpy et al. (1999) demonstrated that equivalent levels of hypotension produced by UCN or hydralazine are associated with decreased inflammatory responses to carrageenin, and the lowered blood pressure correlated with the decrease of inflammatory response. Thus, we suggest that UCN administered i.v. acts as vasodilator, leading to hypotension, rather than as immunologically competent UCN that directly decreases vascular permeability. In this study, UCN was locally administered by inhalation aerosol to lung tissues, which may be insufficient to result in hypotension. Therefore, the effect of UCN on elevation of pulmonary vascular permeability appeared. The effects of UCN on pulmonary vascular permeability remain to be further studied.

In conclusion, our present study demonstrated for the first time that UCN is strongly expressed in rat lung and that inhalation aerosol of UCN increases pulmonary vascular permeability through activation of $\mathrm{CRH}$ receptors. Mast cells and histamine may also be involved in this process as important effector cells and an inflammatory mediator. Peripherally produced UCN in lung may act as an autocrine or paracrine proinflammatory mediator; may be involved in the pathophysiology of some inflammatory lung diseases accompanied by enhanced vascular permeability, such as allergic asthma and pulmonary edema; and may lead to new forms of treatment. The exact physiologic function and pathophysiologic role of UCN in lung remain to be further investigated.

\section{Acknowledgements}

We gratefully acknowledge the kind help by Prof. Xiao Han and the excellent technical assistance of Drs Lingjuan Gao and Jingjing Zhang. We also thank Drs. Xiongfei Zhang and Wenbin Tan for their helpful comments. This work was supported by National Natural Science 
Foundation of China (grant no. 30572185). The authors declare that there is no conflict of interest that would prejudice the impartiality of this scientific work.

\section{References}

Baigent SM \& Lowry PJ 2000 mRNA expression profiles for corticotrophin-releasing factor (CRF), urocortin, CRH receptors and $\mathrm{CRH}$-binding protein in peripheral rat tissues. Journal of Molecular Endocrinology 25 43-52.

Bamberger CM, Wald M, Bamberger AM, Ergun S, Beil FU \& Schulte HM 1998 Human lymphocytes produce urocortin, but not corticotropin-releasing hormone. Journal of Clinical Endocrinology and Metabolism 83 708-711.

Bhuvaneshwari MA, Duraisamy KE, Spyridon CH, Stavros TS, William BO, Vasilis KA, Achilles AT \& Theoharides TC 2003 High levels of intrauterine corticotropin-releasing hormone, urocortin, tryptase, and interleukin- 8 in spontaneous abortions. Endocrinology 144 2285-2290.

Boucher W, Singh L \& Theoharides TC 1996 Differential effect of corticotrophin releasing hormone on rat mast cell secretion. FASEB Journal 10 1290-1292.

Chand N, Pillar J, Diamantis W \& Sofia RD 1985 Inhibition of IgE-mediated allergic histamine release from rat peritoneal mast cells by azelastine and selected antiallergic drugs. Agents Actions 16 318-322.

Chrousos GP 1995 The hypothalamic-pituitary-adrenal axis and immune-mediated inflammation. New England Journal of Medicine 332 1351-1362.

Crofford LJ, Sano H, Karalis K, Webster EL, Goldmuntz EA, Chrousos GP \& Wilder RL 1992 Local secretion of corticotrophin releasing hormone in the joints of Lewis rats with inflammatory arthritis. Journal of Clinical Investigation 90 2555-2564.

Crofford LJ, Sano H, Karalis K, Friedman TC, Epps HR, Remmers EF, Mathern P, Chrousos GP \& Wilder RL 1993 Corticotropinreleasing hormone in synovial fluids and tissues of patients with rheumatoid arthritis and osteoarthritis. Journal of Immunology 151 1587-1596.

Dallal MM \& Chang SW 1994 EB dye in the assessment of permeability-surface area product in perfused rat lungs. Journal of Applied Physiology 77 1030-1035.

Donaldson CJ, Sutton S, Perrin MH, Corrigan AZ, Lewis KA, Rivier JE, Vaughan JM \& Vale WW 1996 Cloning and characterization of human urocortin. Endocrinology 137 2167-2170.

Kageyama K, Bradbury MJ, Zhao LY, Blount AL \& Vale WW 1999 Urocortin messenger ribonucleic acid: tissue distribution in the rat and regulation in thymus by lipopolysaccharide and glucocorticoids. Endocrinology 140 5651-5658.

Karalis K, Sano H, Redwine J, Listwak S, Wilder RL \& Chrousos GP 1991 Autocrine or paracrine inflammatory actions of corticotropin-releasing hormone in vivo. Science 254 421-423.

Katsarou-Katsari A, Singh LK \& Theoharides TC 2001 Alopecia areata and affected skin CRH receptor upregulation induced by acute emotional stress. Dermatology 203 157-161.

Keegan CE, Herman JP, Karolyi IJ, O'Shea KS, Camper SA \& Seasholtz AF 1994 Differential expression of corticotropin-releasing hormone in developing mouse embryos and adult brain. Endocrinology 134 2547-2555.

Kempuraj D, Papadopoulou NG, Lytinas M, Kandere-Grzybowska K, Madhappan B, Boucher W, Christodoulou S, Athanassiou A \& Theoharides TC 2004a Corticotropin-releasing hormone and its structurally related urocotrin are synthesized and secreted by human mast cells. Endocrinology 145 43-48.

Kempuraj D, Papadopoulou N, Stanford EJ, Christodoulou S, Madhappan B, Sant GR, Solage K, Adams T \& Theoharides TC $2004 b$ Increased numbers of activated mast cells in endometriosis lesions positive for corticotropin-releasing hormone and urocortin. American Journal of Reproductive Immunology and Microbiology 52 267-275.

Kishimoto T, Pearse RV, Lin CR \& Rosenfeld MG 1995 A sauvagine/corticotropin-releasing factor receptor expressed in heart and skeletal muscle. PNAS 92 1108-1112.

Liaw CW, Lovenberg TW, Barry G, Olterdorf T, Grigoriadia DE \& De Souza EB 1996 Cloning and characterization of the human corticotrophin-releasing factor-2 receptor complementary desoxyribonucleic acid. Endocrinology 137 72-77.

Linton E, Tilders F, Hodgkinson S, Berkenbosch F, Vermes I \& Lowry P 1985 Stress-induced secretion of adrenocorticotropin in rats is inhibited by administration of antisera to ovine corticotropin-releasing factor and vasopressin. Endocrinology 116 966-970.

Masataka KO, Yutaka KA, Yasunori TS, Akira HA, Ryoji YA, Ken-ichiro IN, Yoshiaki KU, Toshikazu KU, Elenkov IJ \& Chrousos GP 2001 Urocortin expression in synovium of patients with rheumatoid arthritis and osteoarthritis: relation to inflammatory activity. Journal of Clinical Endocrinology and Metabolism 86 4344-4352.

Michael LY, Duraisamy KE, Man H, William BO, Pamela ES \& Theoharides TC 2003 Acute stress results in skin corticotropin-releasing hormone secretion, mast cell activation and vascular permeability, an effect mimicked by intradermal corticotropin-releasing hormone and inhibited by histamine- 1 receptor antagonists. International Archives of Allergy and Immunology 130 224-231.

Mosges R \& Klimek L 1998 Azelastine reduces mediators of inflammation in patients with nasal polyps. Allergy and Asthma Proceedings 19 379-383.

Muglia LJ, Jenkins NA, Gilbert DJ, Copeland NG \& Majzoub JA 1994 Expression of the mouse corticotropin-releasing hormone gene in vivo and targeted inactivation in embryonic stem cells. Journal of Clinical Investigation 93 2066-2072.

Oki Y, Iwabuchi M, Masuzawa M, Watanabe F, Ozawa M, Iino K, Tominaga T \& Yoshimi T 1998 Distribution and concentration of urocortin, and effect of adrenalectomy on its content in rat hypothalamus. Life Sciences 62 807-812.

Okosi A, Brar BK, Chan M, D'Souza L, Smith E, Stephanou A, Latchman DS, Chowdrey HS \& Knight RA 1998 Expression and protective effects of urocortin in cardiac myocytes. Neuropeptides 32 167-171.

Patterson CE, Rhoades RA \& Garcia JGN 1992 EB dye as a marker of albumin clearance in cultured endothelial monolayers and isolated lung. Journal of Applied Physiology 72 865-873.

Petraglia F, Florio P, Gallo R, Simoncini T, Saviozzi M, Di Blasio AM, Vaughan J \& Vale W 1996 Human placenta and fetal membranes express human urocortin mRNA and peptide. Journal of Clinical Endocrinology and Metabolism 81 3807-3810.

Rivier J, Spiess J \& Vale WW 1983 Chemical and biological characterization of rat hypothalamic corticotrophin-releasing factor. PNAS 80 4851-4855.

Saruta M, Takahashi K, Suzuki T, Torii A, Kawakami M \& Sasano H 2004 Urocortin 1 in colonic mucosa in patients with ulcerative colitis. Journal of Clinical Endocrinology and Metabolism 89 5352-5361.

Schulte HM, Chrousos GP, Gold PW, Booth JD, Oldfield EH, Cutler GB Jr \& Loriaux DL 1985 Continuous administration of synthetic ovine corticotrophin-releasing factor in man: physiological and pathophysiological implications. Journal of Clinical Investigation 75 1781-1785.

Schulte HM, Bamberger CM, Elsen H, Herrmann G, Bamberger AM \& Barth J 1995 Systemic interleukin-1 alpha and interleukin-2 secretion in response to acute stress and to corticotrophin-releasing hormone in humans. European Journal of Clinical Investigation 24 773-777. 
Shibahara S, Morimoto Y, Furutani Y, Notake M, Takahashi H, Shimizu S, Horikawa S \& Numa S 1983 Isolation and sequence analysis of the human corticotrophin-releasing factor precursor gene. EMBO Journal 2 775-779.

Singh LK, Boucher W, Pang X, Letourneau R, Seretakis D, Green M \& Theoharides TC 1999a Potent mast cell degranulation and vascular permeability triggered by urocortin through activation of corticotrophin releasing hormone receptors. Journal of Pharmacology and Experimental Therapeutics 288 1349-1356.

Singh LK, Pang X, Alexacos N, Letourneau R \& Theoharides TC $1999 b$ Acute immobilization stress triggers skin mast cell degranulation via corticotrophin releasing hormone, neurotensin, and substance P: a link to neurogenic skin disorders. Brain, Behavior, and Immunity 13 225-239.

Slominski A, Roloff B, Curry J, Dahiya M, Szczesniewski A \& Wortsman J 2000 The skin produces urocortin. Journal of Clinical Endocrinology and Metabolism 85 815-823.

Spina M, Merlo-Pich E, Chan RK, Basso AM, Rivier J, Vale W \& Koob GF 1996 Appetite-suppressing effects of urocortin, a CRH-related neuropeptide. Science 273 1561-1564.

Takao A, Shimoda T, Matsuse H, Mitsuta K, Obase Y, Asai S \& Kohno S 1999 Inhibitory effects of azelastine hydrochloride in alcohol-induced asthma. Annals of Allergy, Asthma and Immunology 82 390-394.

Theoharides TC \& Cochrane DE 2004 Critical role of mast cells in inflammatory diseases and the effect of acute stress. Journal of Neuroimmunology 146 1-12.

Theoharides TC, Singh LK, Boucher W, Pang X, Letourneau R, Webster E \& Chrousos G 1998 Corticotropin-releasing hormone induces skin mast cell degranulation and increased vascular permeability, a possible explanation for its pro-inflammatory effects. Endocrinology 139 403-413.

Theoharides TC, Donelan JM, Papadopoulou NI, Jing C, Duraisamy KE \& Conti P 2004 Mast cells as targets of corticotropin-releasing factor and related peptides. Trends in Pharmacological Sciences 25 563-568.

Torpy DJ, Webster EL, Zachman EK, Aguilera G \& Chrousos GP 1999 Urocortin and inflammation: confounding effects of hypotension on measures of inflammation. Neuroimmunomodulation 6 182-186.

Turnbull AV, Vale W \& Rivier C 1996 Urocortin, a corticotropin-releasing factor related mammalian peptide, inhibits edema due to thermal injury in rats. European Journal of Pharmacology 303 213-216.

Udaka K, Takeuchi Y \& Movat HZ 1970 Simple method for quantitation of enhanced vascular permeability. Experimental Biology and Medicine 133 1384-1387.

Uzuki M, Sasano H, Muramatsu Y, Totsune K, Takahashi K, Oki Y, Iino K \& Sawai T 2001 Urocortin in the synovial tissue of patients with rheumatoid arthritis. Clinical Science 100 577-589.

Vale W, Spiess J, Rivier C \& Rivier J 1981 Characterization of a 41-residue ovine hypothalamic peptide that stimulates secretion of corticotropin and $\beta$-endorphin. Science 213 1393-1397.

Vale W, Vaughan J \& Perrin MH 1997 Corticotropin-releasing factor (CRF) family ligands and their receptors. Endocrinologist 7 3S-9S.

Vaughan J, Donaldson C, Bittencourt J, Perrin MH, Lewis K, Sutton S, Chan R, Turnbull AV, Lovejoy D \& Rivier C 1995 Urocortin, a mammalian neuropeptide related to fish urotensin 1 and to corticotrophin-releasing factor. Nature 378 287-292.

Received in final form 31 December 2005

Accepted 6 January 2006

Made available online as an Accepted Preprint

11 January 2006 